\title{
Analisis Model Mangsa Pemangsa dengan Fungsi Respon Holling Tipe II dan Adanya Mangsa Sakit
}

\author{
Fardinah $^{* 1}$, Laila Qadrini' ${ }^{2}$, Meryta Febrilian Fatimah ${ }^{3}$ \\ ${ }^{1,2,3}$ Universitas Sulawesi Barat \\ e-mail: ${ }^{1 *}$ fardinah@unsulbar.ac.id, ${ }^{2}$ laila.qadrini@unsulbar.ac.id, ${ }^{3}$ merytaff@unsulbar.ac.id
}

\begin{abstract}
Abstrak
Interaksi antara dua populasi yang bersifat mangsa dan pemangsa dapat digambarkan dalam suatu model mangsa pemangsa. Dalam kenyataannya, pemangsa memerlukan waktu untuk berburu dan mengkonsumsi mangsanya yang dapat dinyatakan dalam model fungsi respon Holling Tipe II. Selain itu, dapat pula dijumpai dalam suatu lingkungan adanya populasi mangsa yang sakit yang mengakibatkan kematian karena penyakit tersebut. Penelitian ini bertujuan untuk menganalisis kestabilan model mangsa pemangsa dengan fungsi respon Holling Tipe II yang terdiri dari tiga subpopulasi yaitu mangsa sehat, mangsa sakit dan pemangsa. Jenis kestabilan ditentukan berdasarkan karakteristik nilai eigen yang diperoleh dengan menggunakan kriteria Routh-Hurwitz. Dari penelitian ini diperoleh bahwa tanpa adanya mangsa sakit maka populasi tidak akan pernah eksis sedangkan populasi akan eksis jika ketiga subpopulasi ada dan memenuhi syarat hubungan parameter yang digunakan dalam model tersebut.
\end{abstract}

Kata Kunci: Model Mangsa Pemangsa, Fungsi Respon Holling Tipe II, Kriteria Routh-Hurwitz

\section{PENDAHULUAN}

Pemodelan matematika merupakan cabang ilmu matematika yang merepresentasikan atau menjelaskan masalah di kehidupan nyata kedalam bentuk matematika. Pemodelan matematika biasanya selalu dikaitkan dengan cabang ilmu yang lain seperti biologi, fisika, kesehatan, dan teknik (S. Kant dan V. Kumar, 2017). Dalam cabang ilmu biologi, salah satu bidang ilmu yang mengalami perkembangan adalah ekologi. Perkembangan model matematika realistik dalam ilmu ekologi sangat baik dalam merefleksikan penggunaannya untuk mendeskripsikan permasalahan pada interaksi populasi dengan model matematika yang salah satunya adalah model mangsa pemangsa. Di ekosistem seringkali kelompok mangsa diasumsikan tertangkap dan termangsa oleh pemangsa ketika terjadi predasi (Dawes dan Souza, 2013).

Model mangsa pemangsa pertama kali diperkenalkan oleh Alfred Lotka dan Vito Volterra pada tahun 1926 yang selanjutnya dikenal dengan model Lotka-Voltera. Model Lotka-Voltera adalah model predator-prey yang paling sederhana (A. J. Lotka,1925). Model mangsa pemangsa kemudian terus mengalami perkembangan salah satunya adalah bentuk interaksi antara mangsa dan pemangsa yang dikenal dengan fungsi respon. Fungsi respon dalam ekologi diartikan sebagai jumlah makanan yang dikonsumsi oleh pemangsa sebagai fungsi kepadatan makanan (Panja et al., 2017). Tahun 1953 Holling memperkenalkan fungsi respon yang dikenal sebagai fungsi respon Holling tipe I, tipe II dan tipe III ( Mortoja et al., 2018).

Fungsi respon yang digunakan dalam artikel ini yaitu fungsi respon Holling tipe II. Fungsi respon ini menetapkan bahwa kepadatan populasi pemangsa tidak hanya bergantung pada populasi mangsa, namun juga pada populasi pemangsa itu sendiri (Arditi dan Ginzburg, 1989). Fungsi respon Holling tipe II terjadi pada pemangsa yang membutuhkan waktu dalam mencari dan mengkonsumsi mangsanya. Sehingga dalam tipe II ini penggunaan waktu mulai diperhitungkan dengan sifat pemangsa yang tidak mencari mangsa pengganti ketika mangsa utama punah (Panigoro, 2014).

Selain model ekologi, masalah epidemiologi merupakan salah satu topik hangat dalam pemodelan matematika. Pemodelan matematika dalam epidemiologi memberikan pemahaman tentang mekanisme mendasar yang mempengaruhi penyebaran penyakit. Pada beberapa tahun terakhir penelitian akan ekologi

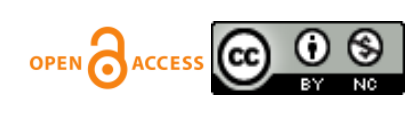


https://jurnal.unsulbar.ac.id/index.php/saintifik

dan epidemiologi banyak dilakukan, meski dua bidang ini berbeda kontribusinya terhadap ilmu pengetahuan namun ada kesamaan diantara keduanya yaitu mencakup makhluk hidup (Maisaroh, Siti, dkk, 2020).

Penelitian mengenai model mangsa pemangsa dengan melibatkan populasi mangsa yang sakit telah dilakukan beberapa peneliti sebelumnya. Hetchcote et.al (2004) meneliti model mangsa pemangsa dengan pertumbuhan logistik dan menggabungkan infeksi dengan pola model SIR (Susceptible, Infectible, Recovered). Sinha et.al (2010) memodelkan mangsa pemangsa dengan pertumbuhan logistik pada mangsa dan infeksi pada mangsa dipengaruhi oleh lingkungan dengan pola SIS. Saadah, Siti, dkk (2019) meneliti model interaksi mangsa pemangsa dengan fungsi respon rasio dependent Holling Tipe II dan perilaku anti pemangsa. Maisaroh, Siti, dkk, (2020) meneliti mengenai Analisis Kestabilan Model Predator-Prey dengan Infeksi Penyakit pada Prey dan Pemanenan Proporsional pada Predator tapi dengan menggunakan fungsi repon Holling Tipe I. Meskipun modifikasi yang dilakukan tidak terlalu signifikan yaitu pada tipe fungsi respon yang digunakan, namun hasil analisis memperlihatkan bahwa terjadi perubahan signifikan pada dinamika dari model dibandingkan model rujukan.

\section{METODE PENELITIAN}

Metode yang digunakan dalam penelitian ini adalah studi literatur dengan prosedur penelitian diberikan sebagai berikut:

1. Membangun model berdasarkan asumsi yang diperoleh dari literatur yang telah dikaji

2. Menentukan titik kesetimbangan model

3. Menganalisis titik kesetimbangan model

4. Melakukan simulasi model

\section{HASIL DAN PEMBAHASAN}

Misalkan didefinisikan $x(t)$ adalah populasi mangsa sehat pada suatu habitat pada waktu $t, y(t)$ adalah populasi mangsa sakit pada suatu habitat pada waktu $t$ dan $z(t)$ adalah populasi pemangsa pada habitat yang sama dengan populasi mangsa pada waktu t.

Asumsi yang digunakan dalam model ini sebagai berikut:

1. Hanya mangsa sehat yang dapat tumbuh. Tanpa adanya pemangsa, mangsa sehat tumbuh secara eksponensial sebesar $\pi$.

2. Infeksi antar mangsa terjadi akibat interaksi, jumlahnya sebanding dengan hasil kali jumlah kedua populasi dengan konstanta $\delta$. Infeksi akan menyebabkan kematian pada populasi mangsa sakit secara proporsional sebesar $\gamma$.

3. Pemangsa berinteraksi dengan mangsa sehat dan mangsa sakit mengikuti fungsi respon Holling Tipe II

4. Terjadi kematian alami pada populasi mangsa sehat dan mangsa sakit sebesar $\mu$ dan pemangsa sebesar $\varphi$

5. Populasi bersifat tertutup

Berdasarkan asumsi tersebut diperoleh model mangsa pemangsa dengan fungsi respon Holling Tipe II dan adanya mangsa sakit yaitu:

$$
\begin{aligned}
& \frac{d x}{d t}=\pi x-\frac{m x z}{1+d x}-\delta x y-\mu x \\
& \frac{d y}{d t}=\delta x y-\frac{n y z}{1+e x}-\gamma y-\mu y \\
& \frac{d z}{d t}=\frac{\alpha x z}{1+d x}+\frac{\beta y z}{1+e x}-\varphi z
\end{aligned}
$$

Titik kesetimbangan persamaan (1) diperoleh dengan menentukan solusi dari $\frac{d x}{d t}=\frac{d y}{d t}=\frac{d z}{d t}=0$. 
Dari persamaan tersebut diperoleh titik kesetimbangan sebagai berikut:

(i) $E_{1}(0,0,0)$

(ii) $E_{2}\left(\frac{\varphi}{\alpha-\varphi d}, 0, \frac{(\pi-m) \alpha}{m(\alpha-\varphi d)}\right)$ dengan syarat $\pi \geq m$ dan $\alpha \geq \varphi d$

(iii) $E_{3}\left(\frac{\gamma+\mu}{\delta}, \frac{\pi-\mu}{\delta}, 0\right)$ dengan syarat $\pi \geq \mu$

(iv) $E_{4}\left(x^{*}, y^{*}, z^{*}\right)$ dimana $x^{*}, y^{*}, z^{*}$ adalah solusi dari sistem:

$$
\begin{aligned}
\frac{d x^{*}}{d t} & =\frac{m z^{*}}{d\left(\pi-\delta y^{*}-\mu\right)}-\frac{1}{d}=0 \\
\frac{d y^{*}}{d t} & =\frac{n z^{*}}{e\left(\delta x^{*}-\gamma-\mu\right)}-\frac{1}{e}=0 \\
\frac{d z^{*}}{d t} & =\frac{\alpha x^{*}}{1+d x^{*}}+\frac{\beta y^{*}}{1+e y^{*}}-\varphi=0
\end{aligned}
$$

Selanjutnya akan dipelajari dinamika di sekitar titik-titik kesetimbangan tersebut. Untuk mengidentififikasi kestabilan lokal dari titik kesetimbangan, dilakukan pelinearan terhadap model (1). Hasil peliniearan memberikan matriks Jacobian dari model (1) yaitu sebagai berikut:

$$
\mathrm{J}=\left[\begin{array}{ccc}
\pi-\left(\frac{m z(1+d x)-m d x z}{(1+d x)^{2}}\right)-\delta y-\mu & -\delta x & \frac{m x}{1+d x} \\
\delta y & \delta x-\left(\frac{n z(1+e y)-n e y z}{(1+e y)^{2}}\right)-\gamma-\mu & -\frac{n y}{1+e y} \\
\frac{\alpha z}{(1+d x)^{2}} & \frac{\beta z}{(1+e y)^{2}} & \frac{\alpha x}{1+d x}+\frac{\beta y}{1+e y}-\varphi
\end{array}\right]
$$

Dengan mensubstitusi $E_{1}$ ke matriks Jacobian (2) diperoleh:

$$
\mathrm{J}_{1}=\left[\begin{array}{ccc}
\pi-\mu & 0 & 0 \\
0 & -\gamma-\mu & 0 \\
0 & 0 & -\varphi
\end{array}\right]
$$

yang memberikan nilai eigen $\lambda_{1}=\pi-\mu, \lambda_{2}=-\gamma-\mu$ dan $\lambda_{3}=-\varphi$. Dengan demikian titik kesetimbangan $E_{1}$ stabil dengan syarat $\pi \leq \mu$.

Dengan mensubstitusi $E_{2}$ ke matriks Jacobian (2) diperoleh:

$$
\mathrm{J}_{2}=\left[\begin{array}{ccc}
\frac{(\pi-\mu) \varphi d}{\alpha} & \frac{-\delta \varphi}{\alpha-\varphi d} & \frac{-m \varphi}{\alpha} \\
0 & \frac{\delta \varphi m-n \alpha(\pi-\mu)}{m(\alpha-\varphi d)}-\gamma-\mu & 0 \\
\frac{(\pi-\mu)(\alpha-\varphi d)}{m} & \frac{\beta \alpha(\pi-\mu)}{m(\alpha-\varphi d)} & 0
\end{array}\right]
$$

yang memberikan nilai eigen $\lambda_{1}=\frac{\delta \varphi m-n \alpha(\pi-\mu)}{m(\alpha-\varphi d)}-\gamma-\mu, \lambda_{2}=\frac{(\pi-\mu) \varphi d}{\alpha}+\sqrt{\left(\frac{(\pi-\mu) \varphi d}{2 \alpha}\right)^{2}-\frac{(\pi-\mu)(\alpha-\varphi d) \varphi}{\alpha}}$ dan $\lambda_{3}=\frac{(\pi-\mu) \varphi d}{\alpha}-\sqrt{\left(\frac{(\pi-\mu) \varphi d}{2 \alpha}\right)^{2}-\frac{(\pi-\mu)(\alpha-\varphi d) \varphi}{\alpha}}$. Dengan demikian titik kesetimbangan $E_{2}$ tidak stabil karena $\frac{(\pi-\mu) \varphi d}{\alpha}>0$ sehingga $\lambda_{2}>0$.

Dengan mensubstitusi $E_{3}$ ke matriks Jacobian (2) diperoleh: 
https://jurnal.unsulbar.ac.id/index.php/saintifik

$$
\mathrm{J}_{3}=\left[\begin{array}{ccc}
0 & -(\gamma+\mu) & \frac{-m(\gamma+\mu)}{\delta+d(\gamma+\mu)} \\
\pi-\mu & 0 & \frac{-n(\pi-\mu)}{\delta+e(\pi-\mu)} \\
0 & 0 & \frac{\alpha(\gamma+\mu)}{\delta+d(\gamma+\mu)}+\frac{\beta(\pi-\mu)}{\delta+e(\pi-\mu)}-\varphi
\end{array}\right]
$$

yang memberikan nilai eigen $\lambda_{1}=\frac{\alpha(\gamma+\mu)}{\delta+d(\gamma+\mu)}+\frac{\beta(\pi-\mu)}{\delta+e(\pi-\mu)}-\varphi, \lambda_{2}=\mathrm{iD}$ dan $\lambda_{2}=-\mathrm{iD}$ dengan $\mathrm{D}=$ $\sqrt{-(\gamma+\mu)(\pi-\mu)}$. Dengan demikian titik kesetimbangan $E_{3}$ stabil dengan syarat $\frac{\alpha(\gamma+\mu)}{\delta+d(\gamma+\mu)}+\frac{\beta(\pi-\mu)}{\delta+e(\pi-\mu)} \leq \varphi$. Dengan mensubstitusi $E_{4}$ ke matriks Jacobian (2) diperoleh:

$$
\mathrm{J}_{4}=\left[\begin{array}{ccc}
J_{11} & -\delta x^{*} & \frac{m x^{*}}{1+d x^{*}} \\
\delta y^{*} & J_{22} & -\frac{n y^{*}}{1+e y^{*}} \\
\frac{\alpha z^{*}}{\left(1+d x^{*}\right)^{2}} & \frac{\beta z^{*}}{\left(1+e y^{*}\right)^{2}} & J_{33}
\end{array}\right]
$$

$\operatorname{dimana} J_{11}=\pi-\left(\frac{m z^{*}\left(1+d x^{*}\right)-m d x^{*} z^{*}}{\left(1+d x^{*}\right)^{2}}\right)-\delta y^{*}-\mu, J_{22}=\delta x^{*}-\left(\frac{n z^{*}\left(1+e y^{*}\right)-n e y^{*} z^{*}}{\left(1+e y^{*}\right)^{2}}\right)-\gamma-\mu$ dan $\mathrm{J}_{33}=$ $\frac{\alpha x^{*}}{1+d x^{*}}+\frac{\beta y^{*}}{1+e y^{*}}-\varphi$. Dengan kriteria Routh-Hurwitz diperoleh bahwa titik kesetimbangan $E_{4}$ akan stabil dengan syarat $J_{11}+J_{22}+J_{33} \leq 0, \mathrm{~L} \leq 0$ dan $J_{11}+J_{22}+J_{33}<\frac{L}{K}$ dimana

$\mathrm{L}=\frac{\delta \mathrm{n} \alpha \mathrm{x}^{*} \mathrm{y}^{*} \mathrm{z}^{*}}{\left(1+e y^{*}\right)\left(1+d x^{*}\right)^{2}}-\frac{\delta \mathrm{m} \beta \mathrm{x}^{*} \mathrm{y}^{*} \mathrm{z}^{*}}{\left(1+d x^{*}\right)\left(1+e y^{*}\right)^{2}}+\frac{\alpha m x^{*} \mathrm{z}^{*} \mathrm{~J}_{22}}{\left(1+d x^{*}\right)^{3}}+\frac{\beta n \mathrm{y}^{*} \mathrm{z}^{*} \mathrm{~J}_{11}}{\left(1+e y^{*}\right)^{3}}+\delta^{2} \mathrm{x}^{*} \mathrm{z}^{*} \mathrm{~J}_{33}$ dan $K=J_{11} J_{33}+J_{22} J_{33}+J_{11} J_{22}+\frac{\alpha \mathrm{mx}^{*} \mathrm{z}^{*}}{\left(1+d x^{*}\right)^{3}}+\frac{\beta \mathrm{ny}^{*} \mathrm{z}^{*}}{\left(1+e y^{*}\right)^{3}}+\delta^{2} \mathrm{x}^{*} \mathrm{z}^{*}$.

Untuk memperkuat hasil analisis yang diberikan sebelumnya, dilakukan simulasi numerik terhadap model (1). Karena keterbatasan data yang ada, pemilihan parameter disesuaikan dengan kondisi kestabilan yang diberikan pada hasil sebelumnya.

Simulasi titik kesetimbangan E1 dipilih parameter sebagai berikut.

$$
\pi=0.1, \mathrm{~m}=0.2, \mathrm{~d}=0.2, \delta=0.2, \mu=0.4, \mathrm{n}=0.2, \gamma=0.05, \alpha=0.3, \beta=0.1, \mathrm{e}=0.2, \varphi=0.5
$$

Diperoleh gambar sebagai berikut:
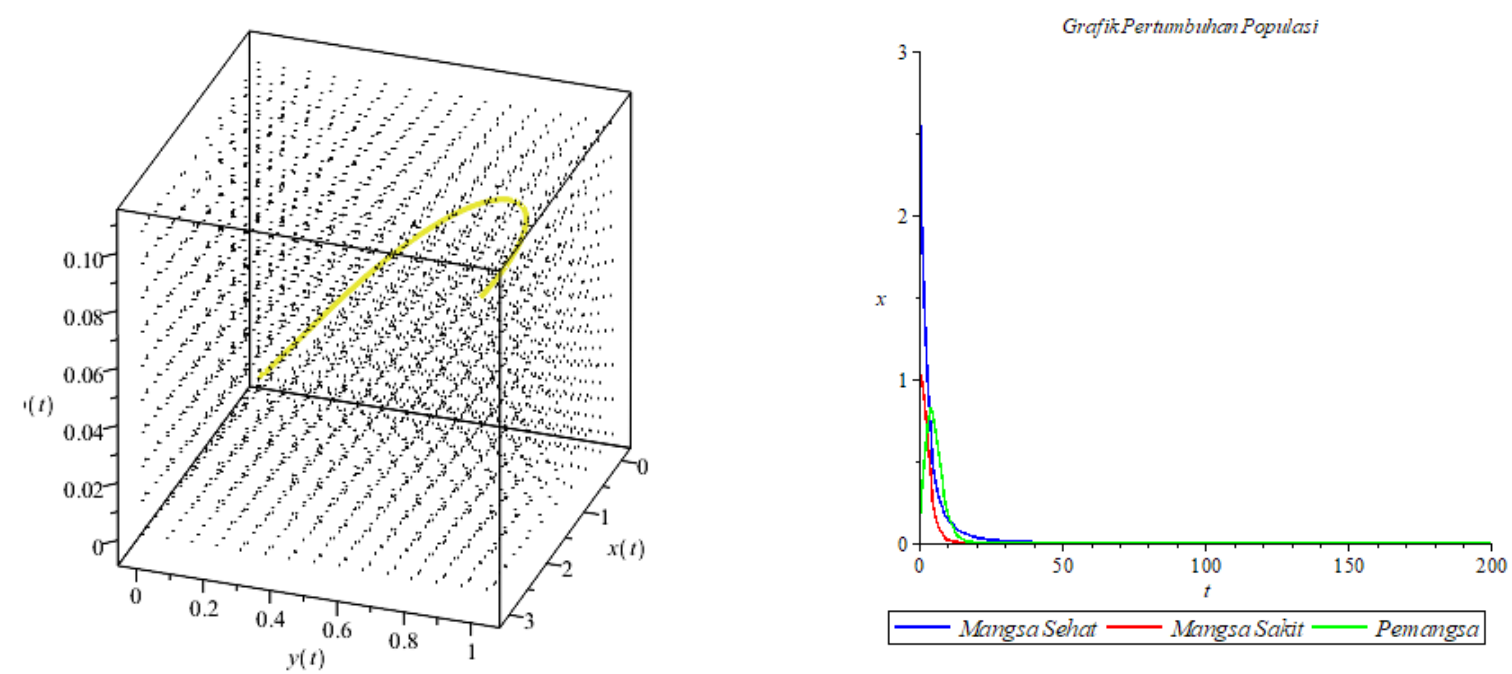

Gambar 1. Simulasi numerik disekitar titik kesetimbangan $E 1$ 
Berdasarkan analisis kestabilan yang dilakukan sebelumnya diperoleh bahwa titik kesetimbangan $E 1$ stabil asimtotik lokal dengan syarat tertentu seperti yang terlihat pada gambar 1. Dari gambar tersebut terlihat bahwa semua subpopulasi menuju kepunahan.

Simulasi titik kesetimbangan E2 dipilih parameter sebagai berikut.

$$
\pi=0.4, \mathrm{~m}=0.2, \mathrm{~d}=0.2, \delta=0.2, \mu=0.1, \mathrm{n}=0.2, \gamma=0.05, \alpha=0.3, \beta=0.1, \mathrm{e}=0.2, \varphi=0.5
$$

Diperoleh gambar sebagai berikut:
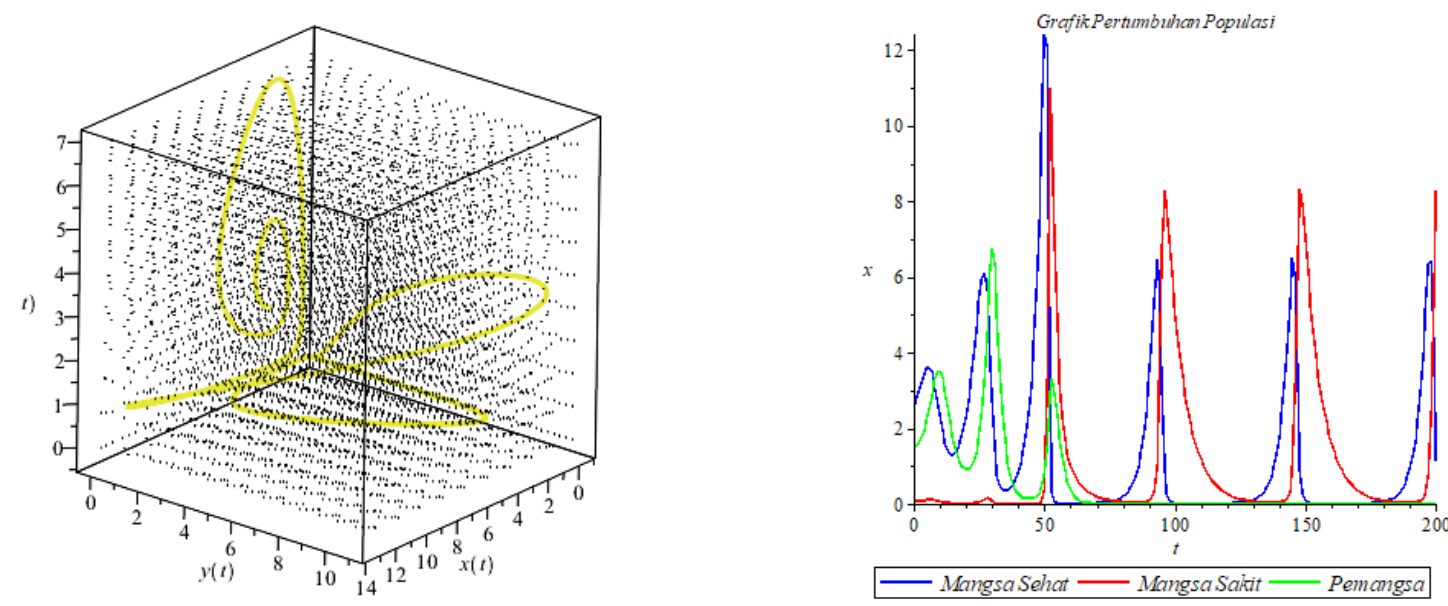

Gambar 2. Simulasi numerik disekitar titik kesetimbangan E2

Berdasarkan analisis kestabilan yang dilakukan sebelumnya diperoleh bahwa titik kesetimbangan E2 tidak stabil seperti yang terlihat pada gambar 2. Dari gambar tersebut terlihat bahwa kehidupan populasi tanpa adanya sub populasi mangsa sakit tidak akan pernah terjadi.

Simulasi titik kesetimbangan E3 dipilih parameter sebagai berikut.

$\pi=0.4, m=0.2, d=0.2, \delta=0.2, \mu=0.1, n=0.2, \gamma=0.05, \alpha=0.3, \beta=0.1, e=0.2, \varphi=0.5$

Diperoleh gambar sebagai berikut:
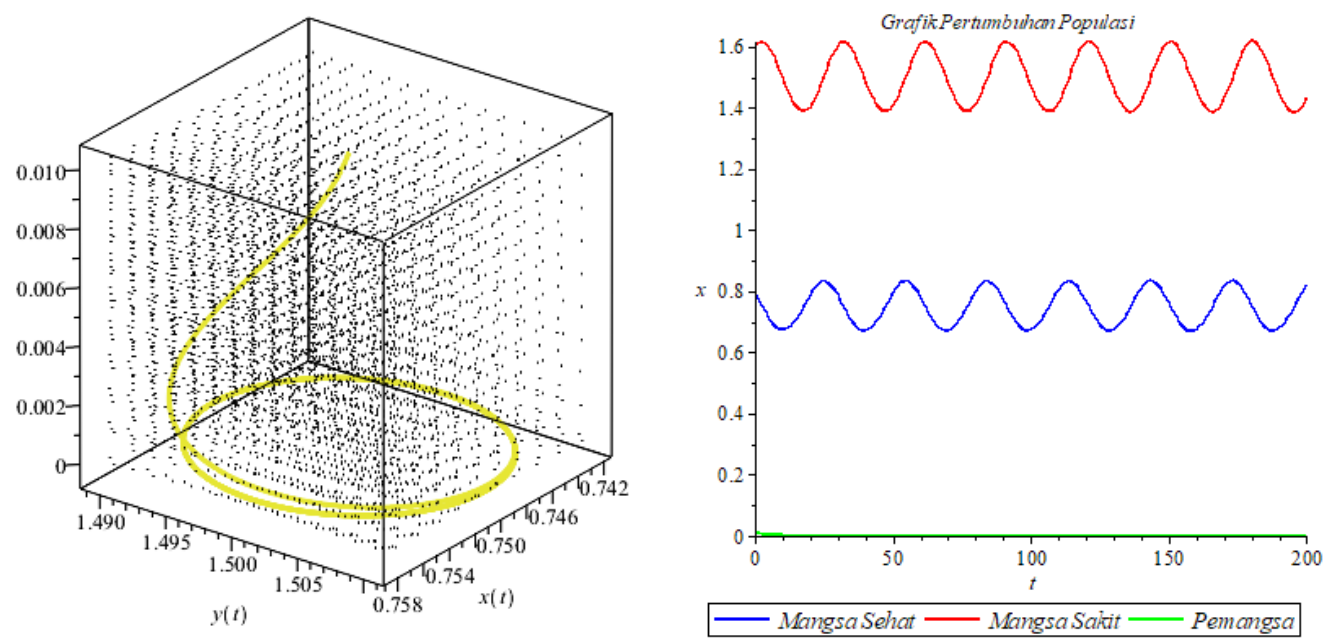

Gambar 3. Simulasi numerik disekitar titik kesetimbangan E3 
Berdasarkan analisis kestabilan yang dilakukan sebelumnya diperoleh bahwa titik kesetimbangan E3 stabil seperti yang terlihat pada gambar 3. Dari gambar tersebut terlihat bahwa jika kita mengambil nilai awal yang cukup dekat dengan E3 maka subpopulasi pemangsa menuju kepunahan sehingga yang tersisa adalah subpopulasi mangsa sehat dan mangsa sakit.

Simulasi titik kesetimbangan E4 dipilih parameter sebagai berikut.

$\pi=0.44, \mathrm{~m}=0.2, \mathrm{~d}=0.0001, \delta=0.85, \mu=0.35, \mathrm{n}=0.001, \gamma=0.05, \alpha=0.8, \beta=0.8, \mathrm{e}=0.7$, $\varphi=0.42$

Diperoleh gambar sebagai berikut:
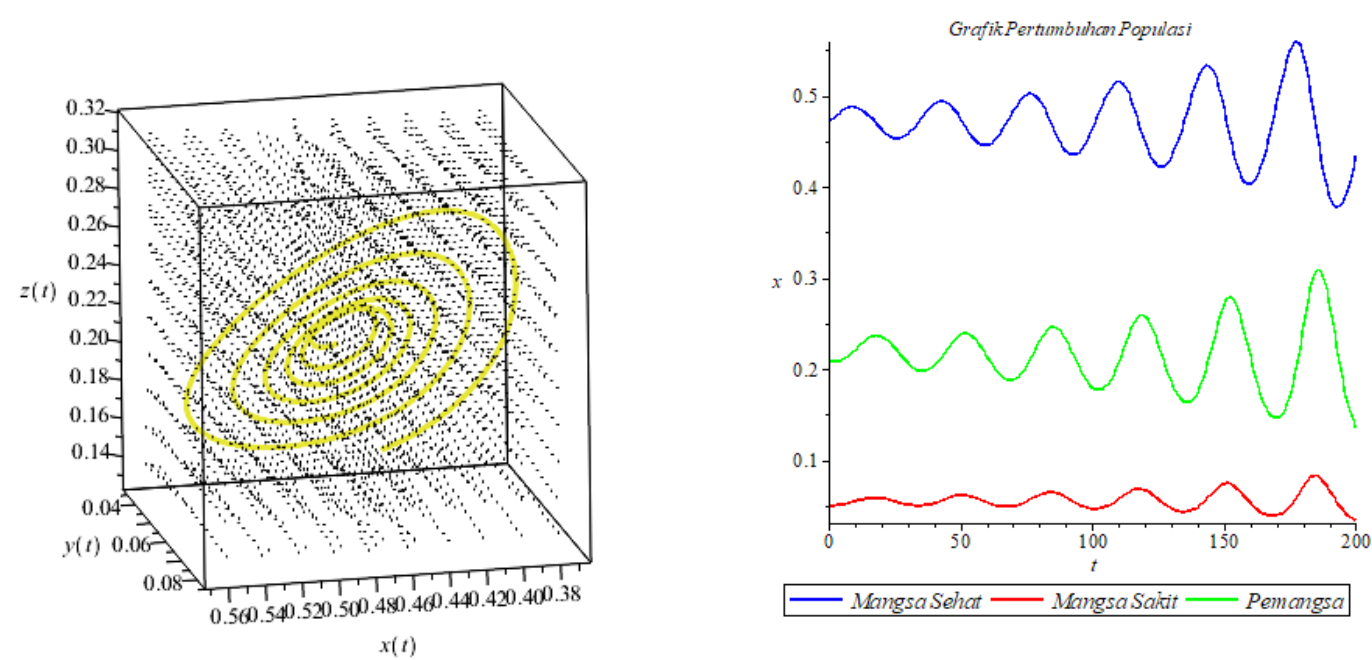

Gambar 4. Simulasi numerik disekitar titik kesetimbangan E4

Berdasarkan analisis kestabilan yang dilakukan sebelumnya diperoleh bahwa titik kesetimbangan E4 stabil seperti yang terlihat pada gambar 4. Dari gambar tersebut terlihat bahwa jika kita mengambil nilai awal yang cukup dekat dengan E4 maka subpopulasi mangsa sehat, subpopulasi mangsa sakit dan subpopulasi pemangsa tidak ada yang mengalami kepunahan.

\section{KESIMPULAN}

Model mangsa pemangsa dengan fungsi respon Holling Tipe II dan adanya mangsa sakit seperti ditunjukkan dalam model (1). Hasil analisis menunjukkan bahwa terdapat empat titik kesetimbangan yaitu titik kepunahan semua subpopulasi, titik kepunahan mangsa sakit, titik kepunahan pemangsa, dan titik eksistensi semua subpopulasi. Kepunahan seluruh populasi mungkin saja dapat tercapai dan kepunahan mangsa sakit tidak akan pernah terjadi. Selain itu hal yang mungkin juga terjadi adalah kepunahan pemangsa dan eksistensi semua subpopulasi jika memenuhi kondisi yang disyaratkan. Di akhir artikel telah ditunjukkan simulasi numerik berupa potret fase dan deret waktu di sekitar setiap titik kesetimbangan serta interpretasi biologisnya.

\section{DAFTAR PUSTAKA}

Arditi, R., and Ginzburg, L. R, 1989, Coupling in Predator-Prey Dynamics: Ratio-Dependence. Journal of Theoretical Biology, vol. 139, hal 311-326.

Dawes, J. H. P., and Souza, M. O, 2013, A Derivation of Holling's Type I, II and III Functional Responses in Predator-Prey Systems, Journal of Theoretical Biology, vol. 327, hal 11-22.

Hethcote, H.W., Wang,W., Han,L., Zhien Ma, 2004, A predator-prey model with infected prey, Theoretical Population Biology, vol 66, hal 259 - 268.

Maisaroh, Siti., Resmawan., Rahmi, Emli., 2020, Analisis Kestabilan Model Predator-Prey dengan Infeksi Penyakit pada Prey dan Pemanenan Proporsional pada Predator, Jambura J. Biomath. vol 1, hal 8-15. 
https://jurnal.unsulbar.ac.id/index.php/saintifik

Mortoja, S. G., Panja, P., \& Mondal, S. K., 2018, Dynamics of a Predator-Prey Model with Stage Structure on Both Species and Anti-Predator Behavior, Informatics in Medicine Unlocked, vol 10, hal 50-57.

Panigoro, H. S., 2014, Analisis Dinamik Sistem Predator-Prey Model Leslie-Gower dengan Pemanenan Secara Konstan Terhadap Predator. Euler, vol 2, hal 1-12.

Panja, P., Mondal, S. K., \& Chattopadhyay, J., 2017, Dynamical Effects of Anti-predator Behaviour of Adult Prey in a Predator-Prey Model with Ratio-Dependent Functional Response, Asian Journal of Mathematics and Physics, vol 1, hal 19-32.

S. Kant and V. Kumar, 2017, Stability analysis of predator-prey system with migrating prey and disease infection in both species, Applied Mathematical Modelling, vol. 42, hal 509-539.

Sinha,S., Misra, O.P., Dhar,J., 2010, Modelling a predator-prey system with infected prey in polluted environment, Applied Mathematical Modelling, vol 34, hal 1861-1872. 